\title{
Age and Second Language Acquisition in Adulthood: The Learning Experiences and Perceptions of Women Immigrants
}

Wendy Wang

\begin{abstract}
Although considerable evidence indicates that age of onset for second language acquisition is related to second-language proficiency outcomes among adult learners, few studies have actually looked at how adult learners of different ages experience and perceive second language acquisition. This study presents 30 women immigrant learners' accounts of their experiences and perceptions of learning English as a second language in the Canadian context. Findings from this study reveal the complexity of adult L2 acquisition, which involves factors pertaining not only to the learners themselves, but also to the social context in which the second language is learned. Implications of these findings are discussed in relation to the second language curriculum development and classroom practice.
\end{abstract}

\section{Background}

Much of the research concerning the role of age in second language acquisition has centered on identifying the close of an alleged critical period for $\mathrm{L} 2$ acquisition, indicating that there is gradual linear decline in learners' ultimate attainment ${ }^{1}$ in $\mathrm{L} 2$ as a function of age, and this decline continues until puberty (Johnson \& Newport, 1989; Flege, 1992; Oyama, 1976; Palij, 1991; Patkowski, 1980; Thompson, 1991; see Long, 1990; Singleton, 1989, for reviews). These findings have been interpreted as "evidence for a critical or sensitive period, a maturationally determined point of heightened receptivity to environmental stimuli" (Bialystok, 1997, p. 116). It is argued that beyond the critical or sensitive period, age ceases to have a systematic effect on L2 acquisition. Instead there is great variability and a lack of linearity in L2 attainment among adult learners (Johnson \& Newport, 1989; Patkowski, 1980). However, Bialystok and Hakuta's (1994) recent reinterpretation of Johnson and Newport's (1989) study, the latter considered by many second language researchers to have provided decisive support for a sensitive period in the acquisition of L2, emphasized that "there is a linear decline in performance with age of arrival, although the decline is steeper for the younger than the older arrivals" (p. 69). In fact, "the steepest decline occurs in a linear fashion before age twenty, at which the decline becomes less steep" (p. 72, emphasis added). This suggests that there is a general pattern of lower 
attainment in L2 associated with increasing starting age; however, "this pattern does not appear to come to an end at around puberty but may persist into the 20 s at least, with a continuing, somewhat less precipitous pattern of declining outcomes across mature adult starting ages" (Harley \& Wang, 1997, p. 37). Bialystok and Hakuta's (1994) observation finds its support in the accumulating evidence from adult learners suggesting that differential proficiency outcomes in L2 continue to be related to learners' age of arrival in the L2 environment, although the declining outcomes with increasing starting age have been reported to be most strongly manifested in the aural-oral aspects of L2 proficiency (d'Anglejan \& Renaud, 1985; von Elek \& Oskarsson, 1973; Klein \& Dittmar, 1979; Scott, 1994; Seright, 1985; Wang, 1998).

A predominant method of studying the age issue in these studies has been the use of statistical analyses. Quantitative data in these studies are important in uncovering the linear relationship between declining L2 proficiency outcomes with increasing age, yet there is no agreement as to what may underlie the effect of age on adult L2 acquisition. Klein and Dittmar (1979) found a strong inverse relationship between age of arrival and L2 oral syntactic proficiency ratings and concluded that age may co-vary with exposure to the L2, as the younger adults (aged 18 to 21) they studied had more contact with native speakers than the older ones (aged 30+). Like Klein and Dittmar, Scott (1994) associated the higher achievement in L2 listening comprehension by the younger adult learners (aged 21-25) in her study with greater contact with native speakers. It is worth noting that Scott did not find significant differences between the younger and older adults on the measure of short-term memory capacities, but concluded that reduced hearing acuity among the older adults (aged 50-71) might have contributed to their lower achievement in L2 listening comprehension. Seright's (1985) study demonstrated a strong age effect in adults' (aged 17-41) achievement in listening comprehension, but failed to reveal what may underlie the age effect other than the pre-test scores. D'Anglejan and Renaud (1985), who explored the relative importance of a variety of learner variables with respect to individual differences in overall achievement in French as an L2, suggested that nonverbal intelligence along with years of schooling, age, and use of French accounted for the greatest proportion of variance in overall achievement in French. In addition, the researchers speculated that the inverse relationship between age and French achievement found in their study was presumably due to "little motivation to learn the second language among older immigrants who live within the confines of tightly knit and protective family units or ethnolinguistic groups" (p. 13). Wang's (1998) recent study of two age-of-arrival groups of adult learners demonstrated a strong effect of starting age on learners' oral English proficiency outcomes. A comparison of the two groups was conducted on the measures of several learner variables such as L2 contact, intelligence (crystallized and fluid intelligence ${ }^{2}$ ), memory, 
and attitudes/motivation. The results of the analyses highlight the importance of fluid intelligence and variety of $\mathrm{L} 2$ contact and use in learners' oral English development. On these learner variables, which correlated positively with learners' oral English proficiency outcomes, the earlier arrivals (aged 25-35) had an advantage over the later ones (aged 40-55). However, like Scott, Wang did not find any significant difference either between the two age-ofarrival groups in terms of their short-term memory capacities or in their attitudes/motivation. In fact, on the measure of attitudes/motivation, both groups showed positive attitudes and high motivation to learn ESL.

Although the learner variables investigated in these studies may offer some plausible clues as to what may account for the effect of age on adult L2 acquisition, far more information is needed if we are to draw any conclusions about how different age groups of adult learners learn and how they may vary. What is obviously lacking in research on the possible explanations of the effect of age in adult L2 acquisition are the views of adult learners who are involved in the phenomenon under study. Because age of arrival is negatively correlated to learners' $L 2$ proficiency outcomes as indicated in the studies reviewed above, studying this phenomenon from the perspective of the adult learners may provide important new insights. However, remarkably few studies have actually examined this question from the learners' perspective. This study, which is a complementary aspect of the quantitative study I conducted on the age-related effects in adult second language acquisition (Wang, 1998), fills the gap by using an interview approach to obtain descriptive information on how two different age-of-arrival groups of adult learners perceived and experienced learning ESL and how they interpreted their experiences to construct an understanding of the issue of age and L2 acquisition in adulthood.

\section{The Interview as a Research Tool}

The interview is a qualitative technique that has been successfully used in many fields. In recent years, interviews have been increasingly employed in studies of affective factors in L2 learning (Price, 1991) and in studies of adult ESL literacy (Cumming \& Gill, 1992; Klassen \& Burnaby, 1993; Mellow, 1992). These studies have demonstrated the benefits of using interviews as a useful approach to explore the personal and experiential aspects of the complex issue of adult L2 acquisition. The present use of interview as a research tool is the first attempt that I know of in studies of age-related differences in L2 acquisition. I selected it for the following two reasons. First, the interview is a natural and generative medium for hearing learners' interpretations of lived experiences of learning an L2. Second, the interview can be used both to obtain an "authentic" description of the interviewees' own experiences and to investigate specific questions of interest to the researcher. In recognition that adult L2 acquisition involves many previously unex- 
plored and inadequately described variables, I have come to appreciate the interview as a powerful tool that allows me to gain a sense of how adult learners perceive and experience learning an L2, and to use their insights as a source of information in addressing the issue of age and adult L2 acquisition.

\section{Participants}

As part of my doctoral research on age-related effects in adult $\mathrm{L} 2$ acquisition, I interviewed two groups of adult learners: one group of 15 learners whose age of arrival (AOA) in Canada was between 25 and 35 (referred to as earlier AOA group), and another group of 15 learners whose AOA in Canada was between 40 and 55 (referred to as later AOA group). The 30 voluntary participants were female Mandarin-speaking immigrants learning ESL in the Canadian context. The choice of homogeneous first language (L1) controls for the possible effects of L1 as well as cultural effects on their experiences and perceptions of learning ESL. These participants were recruited through the LINC (Language Instruction for Newcomers to Canada) program offices across Metropolitan Toronto. This federally funded, basic language training program is offered to new immigrants in local communities throughout English-speaking Canada. The stated goal of LINC is the development of learners' communicative competence in English in order for them to be able to participate in Canadian society (LINC Curriculum Guideline, 1994, p. 7). As measured by LINC assessors using A-LINC (Assessment Tool for Language Instruction for Newcomers to Canada), all the participants were initially assessed as LINC Level 1 for their English proficiency at entry to the program. To ensure that these learners had had time to acquire some proficiency in English, all those included in this study had resided in Canada for a minimum of six months at the time of my data collection, with a maximum length of residence of 69 months. The two AOA groups of adult learners were comparable in terms of their length of residence $(z=-.56, p=.58)$ and years of L1 education $(z=-1.14, p=.26)$; but the later AOA group had had the advantage of receiving more ESL instruction since their arrival in Canada $(z=-2.10, p<.05)$ (Wang, 1998).

\section{Data Collection}

The 30 participants were individually interviewed with open-ended questions to gather information on their perceptions and experiences of learning ESL in the Canadian context. Following the testing phase of the quantitative study on the age-related effects in adult second language acquisition (Wang, 1998), three primary types of information were requested: (a) experiences with English; (b) perceptions of oral English development; and (c) perceptions of age and L2 acquisition. I conducted the interviews in Mandarin. During the interviews, the following three sets of questions were asked: 
1. Describe your learning experience. Is it difficult for you to learn English? What is it that makes it most difficult for you? In terms of speaking, listening, reading, and writing, in which aspect do you think you have made most progress since your arrival? Do you think you have favorable learning conditions to learn English? What obstacles have you experienced in learning English?

2. How long do you think it will take for you to be able to speak English fairly fluently? What do you consider the best method to improve your oral English? Do you think oral English is better learned through use or by rote? $?^{3}$

3. How would you rate your memory? Are you able to remember what you have learned in class and use it in social contexts? Do you think age is a factor in learning a second language? If yes, in what way?

During the interviews, I posed the same questions for the earlier and later arrivals, although the questions were not always phrased precisely as drafted because I also tried to achieve a natural flow to each individual conversation. The interviews were taped-recorded and later transcribed for descriptive analyses. Note that the quality of responses was unavoidably uneven. Some participants were more articulate, and their answers were more extensive than those of others. Also, not everyone answered all the questions; therefore, the percentage reported below is the percentage of received responses.

\section{Findings}

In this article I report on how the two different AOA groups of adult women immigrants experienced and perceived learning ESL and what they considered as barriers to their L2 acquisition.

Learners' experiences with English. The first set of interview questions concerned learners' experiences in learning ESL. Most learners $(66 \%)^{4}$ reported that it was difficult for them to learn English; $21 \%$ indicated it was very difficult, whereas $14 \%$ reported that it was not difficult. The responses of the earlier and later AOA groups were remarkably similar. It was interesting to note that those who did not consider learning English as difficult drew a distinction between learning English and using English. For them it was not difficult to learn English analytically, but to use English in oral communication remained a challenging task: "I don't think it is difficult to learn English. It is not learning that is difficult. For me the difficulty is how to use it" (EL:15). ${ }^{5}$

A great majority of learners across the two AOA groups (72\%) reported learning to speak as the most difficult aspect of learning English; however, the difficulties they experienced varied. Twenty-one percent of the earlier arrivals versus $47 \%$ of the later arrivals mentioned that they experienced particular difficulty in pronunciation: 
"Sometimes the teacher corrects my pronunciation. It's very hard for me to correct myself. (EL:03)

I think my pronunciation is not accurate.... When I speak English, it's very difficult for me to pronounce the words accurately. English pronunciation is very difficult for me. (LL:17)

Some learners expressed great difficulty in listening comprehension:

The difficulty is I can't understand ... I can never understand what they are saying. (LL:22)

Listening comprehension is extremely difficult because they speak very fast. Listening comprehension is most difficult for me. (LL:28)

The learners who mentioned specific difficulty in listening comprehension were all later arrivals (40\%), whereas none of the earlier arrivals reported this. These differences between the two AOA groups regarding pronunciation and listening comprehension are consistent with learners' responses to the question on the aspect of language in which they had made most progress since their arrival. Although $67 \%$ of the earlier arrivals reported that they made most progress in listening comprehension, only $33 \%$ of the later arrivals reported this. Similarly, more earlier arrivals (25\%) than later arrivals (8\%) reported making most progress in speaking English. In contrast, $42 \%$ of the later arrivals versus $8 \%$ of the earlier arrivals reported making most progress in writing English, and $33 \%$ of the later arrivals versus $8 \%$ of the earlier arrival reported making most progress in reading English.

Forty-eight percent of the learners across the two AOA groups also indicated experiencing difficulty in learning English vocabulary. Most attributed this difficulty to their "failing" memories. In this respect, differences between the two AOA groups were much narrower. The following quotations from the interviews illustrate their frustrations:

Vocabulary is difficult. My memory is not good. It's very difficult for me to remember [the English words]. I just can't remember the new words. (EL:01)

I think it's very difficult. The vocabulary is so large that it's very difficult for me to remember. My memory is not good any more. I can't remember. (EL:03)

I think my biggest problem is vocabulary ... If I run into a new word, I'll have to look it up in the dictionary five to 10 times before I can remember it. I just can't remember it. It seems as if I have never seen it before.

No trace at all. (EL:06)

However, only a few learners across the two groups (14\%) considered grammar as the most difficult aspect of learning English. But this does not 
mean that they had no problems using grammar, as illustrated in the following quotation:

As to grammar, it's easy to understand, and I know how it should be used. But when I speak, my grammar is gone. But when I write, I know what tense to use. (EL:04)

A substantial number of learners, $57 \%$ of the earlier arrivals versus $43 \%$ of the later arrivals, experienced difficulty, not so much in speaking itself, but rather in getting access to meaningful language-acquisition contacts to learn and practice speaking English:

I think it's very difficult to learn English. The difficulty is lack of opportunities to speak [English]. (EL:02)

I think it's difficult to learn English ... My difficulty is in speaking. I seldom speak. There is no opportunity to speak [English]. (EL:10)

When I first came to Canada, I forced myself to learn English. I didn't find it difficult at first. As long as you often speak English and hear it spoken, [it shouldn't be]. But I don't have the [language] environment. (LL:24)

Those who tried to gain access to exposure to English found that it was not totally at their disposal. In describing their attempts to practice English at home, some reported the following:

I have no one to speak English to. I thought about speaking English with my husband at home, but it's not practical. (EL:10)

Nobody speaks English at home. This is the least favorable environment. I want to speak English to my son, but he doesn't want to. (LL:22)

Some learners who had access to an English-speaking environment reported that once they had the opportunity to speak English, they often had to confront the reality of being unable to engage people in a conversation however much they wanted to, as suggested in the following quote:

At work, I try to talk rubbish [referring to broken English]. I just talk; I don't care if it's right or wrong. They all know I can't speak well. So they don't care what I say. They don't listen. (LL:19)

However, most $(86 \%)$ considered themselves to have fairly favorable learning conditions as compared with learning English as a foreign language in their native land. When asked whether they had experienced any barriers to their learning English, their responses varied, but they were in many ways similar across the two AOA groups. Some learners (29\%) reported having no barriers, which can be taken as an indication that these learners tried to control their own learning and attributed their success or failure to their own 
efforts. Thirty-six percent of the learners reported that their biggest barrier was lack of opportunities to learn and practice their oral English:

As to barriers, the barrier that I have is everybody in the family speaks Chinese. If everybody spoke English, I wouldn't have any barrier. (EL:10)

The biggest hurdle for me is lack of opportunities to speak [English]. (LL:23)

Some learners $(21 \%)$ considered themselves the barrier to learning, as illustrated in the following quotations:

[My learning condition] is supposed to be good. The barrier is myself. I have the language environment; I have help from friends, but I just can't get into speaking English. I usually don't speak English. (EL:14)

I have psychological barriers. I seldom speak [English]; sometimes I am afraid to open my mouth to speak [English]. (LL:24)

Further barriers indicated by the learners across the two AOA groups included failing memory, personal commitments to other matters (e.g., family responsibilities, employment), pronunciation, and reading. Although there were similarities between the earlier and later AOA groups in their responses, there were some salient differences as well. Those who considered failing memory as the major barrier to their learning of English were all later arrivals, representing $29 \%$ of the later AOA group. As mentioned above, the earlier arrivals also complained about their memories failing them, but none reported it as an important barrier to learning. In contrast, of those who viewed an inadequate language environment as an important barrier, 60\% were earlier arrivals and $40 \%$ were later arrivals.

Learners' perceptions of oral English development. The second set of interview questions concerned the learners' perceptions of oral English development. Learners were asked to estimate the length of time necessary for them to be able to speak English fairly fluently. Most learners believed that a reasonable level of oral proficiency in English was achievable; however, their estimates of further time needed varied over a full range of possibilities, from half a year $(9 \%)$ to 1 year $(4 \%), 2$ to 3 years $(26 \%), 3$ to 5 years $(13 \%)$, impossible $(22 \%)$, and not sure $(17 \%)$. These estimates, however, were made based on their current learning situations.

A striking difference was found in regard to the two AOA groups' estimates of the time necessary to develop oral English fluency. The earlier arrivals appeared to be more optimistic about the prospect of their L2 proficiency than the later arrivals. In fact, two earlier arrivals considered themselves to be relatively fluent speakers already, and some earlier arrivals 
claimed that, given the most favorable language learning environment, the length of time needed could be considerably shorter. For example,

If I had a speaking partner to practice English with, I am quite confident that I would be able to speak English very well in half a year. (EL:06)

I think if I had a very good language learning environment, it would take me three months to half a year to be able to speak English very well. I think environment is extremely important. (EL:15)

In contrast, those who considered it impossible to achieve a reasonable level of oral fluency were all later arrivals, representing $42 \%$ of the later AOA group.

It'll be very difficult for me. I don't think it's possible. It'll be something if only I could understand [when people speak English]. To be able to express myself will be difficult. (LL:23)

In response to interview questions concerning their perceptions as to how oral English is most effectively learned, most of the learners considered that the best way to learn oral English was to be exposed to an English-speaking environment and to practice speaking English with English-speaking Canadians; however, very few reported being able to do so. In fact, both AOA groups expressed great disappointment at their lack of opportunity to learn and practice oral English.

On the question of whether oral English could be better learned through use or by rote, the two AOA groups responded differently. An overwhelming majority of the earlier arrivals (93\%) believed in learning English through using it. In comparison, only $60 \%$ of the later arrivals shared this belief, with a substantial $40 \%$ considering that English could be better learned by rote.

Learners' perceptions of age and L2 acquisition. The third set of interview questions concerned learners' perceptions of the relationship between age and adult L2 acquisition. An overwhelming majority of the learners across the two AOA groups ( $83 \%$ ) endorsed the common belief that age affects L2 acquisition, whereas only $14 \%$ of the earlier arrivals and $20 \%$ of the later arrivals did not believe so.

In reference to how age may affect $\mathrm{L} 2$ acquisition, there were more similarities than differences in the responses of the two AOA groups. Fiftynine percent of all the learners held age directly responsible for their declining memories:

I think it's very difficult for me to learn English because my memory is not good. I think maybe because I'm getting older and my memory is very bad. I forget whatever I learn. (LL:17) 
The difficulty for me is I can't remember [what I've learned]. This has to do with age. I just can't remember any more. Sometimes I study very hard. For example, when I study the Bible, I copy the new words. Then I work very hard to remember them, and then I forget everything. (LL:22)

One factor is age. It has to do with age. I learn a little and then I forget a little. I forget whatever I learn. (LL:24)

However, when learners were asked to self-evaluate their memories, differences between the two AOA groups were observed. Seventy-one percent of the earlier arrivals claimed that their memory was so-so, and $29 \%$ claimed that their memory was bad. In comparison, the later arrivals were more negative: $40 \%$ of the later AOA group claimed that their memory was so-so, $47 \%$ claimed that their memory was bad, and $13 \%$ claimed that their memory was very bad.

Fourteen percent of all the learners believed that their tongue muscles were getting stiffer with age, which affected their pronunciation, and $7 \%$ associated age with slow responses. However, one striking difference between the two AOA groups was that $20 \%$ of the later arrivals (and none of the earlier arrivals) believed that adults would never successfully learn an L2 as children do because they could never have the natural language environment that children enjoy. For instance,

Language has to be learned early. Like my son, he doesn't work hard, but he plays around at school and now he speaks very well. I go to school too, but my progress is minimal. (LL:22)

Maybe because I have very limited contact to speak English and to listen to it. My daughter, the reason why she learns so fast is because people around her speak English. (LL:24)

On the other hand, $21 \%$ of the earlier AOA group associated age with more commitments in adult life, resulting in a lack of concentration and energy for learning English as indicated in the following quotations:

As you get older, you have a family and other commitments. Your life is wider and with lots of things bothering you. So you don't have the energy to learn. When you learn, you're likely to forget. (EL:07)

I can't concentrate [on learning English], not like I used to when I was young. It is impossible now. Sometimes I have confidence, but when I get home, there are so many things to worry about, such as job, housing, daily life problems. So many problems at the same time. (LL:23) 


\section{Discussion}

The above descriptive accounts of learners' experiences and perceptions of learning ESL reveal some salient differences as well as similarities between the two AOA groups. These findings provide an additional perspective on quantitative findings from previous research and suggest several possible variables that may have a bearing on these adult learners' acquisition of English.

First, it was apparent that both AOA groups experienced a lack of situations where they could learn to speak and practice English. For many, their inability to find opportunities to speak English created a great deal of frustration. Although the lack of access to a language environment among these adult learners could be gender-related (Burton, 1993; Nyikos, 1990), the present finding is in accord with d'Anglejan and Renaud's (1985) observation that most immigrant learners they studied had very limited social contact with native speakers (Hart \& Cumming, 1997). D'Anglejan and Renaud speculated that this might result from a settlement pattern (e.g., immigrants had the tendency to reside in an area populated by other immigrants), which may be responsible for the lack of motivation among immigrants, particularly older immigrants, to learn the target language. However, the interview data revealed that behind learners' high motivation, which was found in the quantitative aspect of the study, were their frustrations at being unable to have access to language-acquisition contacts that they desperately needed and wanted. In fact, what seems to best characterize both groups in this study is their strong desire to have meaningful language-acquisition contacts and their desperate feeling of being unable to do so. This clearly indicates that wanting to have language-acquisition contacts is very different from being able to establish them (Horwitz, 1987). A thorough understanding of this gap requires viewing $\mathrm{L} 2$ learning broadly. A relevant limitation to adult L2 learning theories, as Peirce (1995) points out, has been "the premise that language learners can choose under what conditions they will interact with members of the target language community and that the language learners' access to the target language community is a function of the learners' motivation" (p. 12). However, the motivation factor considered by Schumann (1975, 1976) and Gardner (1985) cannot provide an adequate explanation for the particular difficulty that these women immigrant learners experienced in getting access to meaningful language-acquisition contacts despite their strong desire to do so. The learners' attempts and failures to capitalize on opportunities for L2 use illustrate that other factors were clearly at work. Obviously, for the success of any linguistic encounter the learner needs not just motivation, but also the willing participation of the another person (Peirce, 1995). In any case, the role of motivation in L2 acquisition needs to be better formulated in terms that are relevant to the situations of adult im- 
migrant learners, particularly women (Cumming \& Gill, 1992). An alternative way to make sense of the present findings is in reference to the paradoxical positions of the participants in Peirce's (1993) study: "on the one hand, they need access to anglophone social networks in order to practice and improve their English; on the other hand, they have difficulty gaining access to these networks because common language is a priori condition of entry to them" (p. 78). With low proficiency in English, it is conceivable that many of the women immigrant learners' access to English-speaking social networks was severely restricted as shown in the following quotation:

I have obstacles; that is, I don't have a job and I can't find a job in an

English-speaking environment. This is the biggest hurdle. (EL:02)

The denial of access to one of the most meaningful language-acquisition environments illustrates that most adult immigrants learn ESL under conditions of social marginalization (Peirce, 1995).

Second, contrary to common belief, only a few learners across the two AOA groups considered grammar as the most difficult aspect of learning English. This finding clearly indicates, in line with Singleton's (1989) generalization, that adult learners perceive little difficulty in recognizing and assimilating the grammatical system of an L2. However, it strikes me as more than a coincidence that a substantially larger number of earlier arrivals perceived themselves to have made most progress in listening and speaking since their arrival, whereas most later arrivals felt they had made most progress in reading and writing English. The particular difficulty experienced by some later arrivals in pronunciation and listening comprehension may have contributed to their low rating in aural-oral skills. This finding is consistent with results from the quantitative aspect of the study that the earlier arrivals outperformed the later arrivals on three measures of oral English proficiency. It is also in accord with results from previous studies, particularly Seright's (1985) study, which suggested that, given the same time span and similar learning conditions, adults' achievement in L2 listening comprehension declined with increasing age.

Third, interesting differences were observed between the two AOA groups in their perceived obstacles to L2 acquisition. The earlier arrivals tended to perceive lack of language environment as the major barrier to learning, whereas later arrivals tended to consider failing memory as the major barrier. Such a difference in their perceptions of barriers may reflect their ways of learning, suggesting a tendency for the later arrivals to place more reliance on memorizing L2 and for the earlier arrivals to rely more on obtaining language-acquisition contacts, a perception that may have encouraged the latter to be more open to new experiences in L2. This provides a possible explanation for the consistent findings suggesting that younger 
adults tended to have more contact with L2 than the older ones (Klein \& Dittmar, 1979; Scott, 1994; Wang, 1998).

Although the later arrivals' preference for learning by rote could be a reflection of their personal learning styles, the interview data revealed that it may also be suggestive of a higher level of anxiety and lack of confidence among the later arrivals. LL:24 brought out this point when she said:

If I pick up a book and read it, for me that is easy and I am not afraid because you just read. But in oral communication, I will panic and get frustrated. (LL:24)

The communication and interpersonal anxiety experienced by this learner could be associated with her oral skills (Spolsky, 1989); it is also likely to result from the way learners process $\mathrm{L} 2$ :

Chinese and English are so different. I am used to [Chinese], so I often make mistakes [in English]. Subjectively, we are likely to bring Chinese into English, like a transfer. When you ask me a question, I translate it into Chinese, and then translate [what I want to say in Chinese] into English. This is how I respond. (LL:21)

When I speak, it's very, very difficult as if I have obstacles, very straining. That's because I have to translate Chinese into English, and then translate it back into Chinese. I can't handle it. (LL:28)

These learners' experiences clearly illustrate that "The adult's standard of comprehension ... is likely to be his ability to translate what he hears into his own language-a very high standard, indeed" (Burling, 1981, p. 286). In a similar way, they are likely to translate what they want to say in their L1 into an L2 that they are still struggling with. For many of the adult learners in this study, it was this high standard of comprehension and the constant predicament of being tempted to say more than their linguistic resources allowed that created a lot of anxiety and frustration.

Fourth, the difference between the two AOA groups in their estimates of further time needed to develop oral fluency is also noteworthy. The earlier arrivals' optimistic estimates can be taken as an indication of self-confidence, which is critical to learners' development of their expectations for and commitment to L2 acquisition. A belief that it would take them forever to achieve a reasonable level of oral proficiency is obviously discouraging and is likely to have affected the later arrivals' efforts and commitment to their L2 learning. If, as Keller (1983) argued, language learners who think they are likely to succeed are more likely to be successful than those who expect to fail, then the earlier arrivals' optimistic anticipation of success could have had a positive impact on their L2 acquisition. Their optimistic anticipation is also suggestive of their positive learning experiences, which are likely to help sustain their motivation to learn ESL (Clément, 1980). 
Fifth, the apparent differences between the two AOA groups in their self-evaluations of their memory capacities form an interesting contrast to results from the quantitative aspect of the study, suggesting that the two AOA groups were comparable on the measures of short-term memory capacities, a finding in line with the general consensus that there is no systematic decline in memory capacities among adults (Siegel, 1994), at least not until in late adulthood (Fozard, Nuttal, \& Waugh, 1972). However, as indicated in the interview data, the earlier arrivals appeared to be more confident about their memory capacities than the later arrivals. The later arrivals' lack of confidence in their memory can be better understood with reference to the finding that a substantial number of later arrivals considered English could be better learned by rote. It is conceivable that their emphasis on learning by rote may have led them put undue demands on their memory, only to feel disappointed when it let them down. In addition, the interview data bring out the issue of the relationship between memory and the way L2 is learned. As indicated in the following quotes, it might not be as much their memory failing them, but rather the way they study English:

I can remember most of the words, but if I don't use them, I'll forget all. (EL:02)

There is no use remembering new words. You can only learn in practice. I've never learned words of chemistry, but because I need to use them, I remember them very fast. (LL:22)

My memory is not good. What I learn in the morning, I may not remember in the afternoon. But when I took my daughter shopping for clothes [the other day], the salesperson repeated "style" and I remember it. But I can't remember what the teacher teaches [in the classroom]. (LL:29)

These learners' observations illustrate that memory seemed to work best when learners had opportunities and necessities to use the language. This may suggest that as much as memory capacity counts in L2 acquisition, its effect is likely to be exaggerated if L2 is learned in isolation. Obviously, for many of the adult learners in this study, especially the later arrivals, learning English with limited chances of using it in meaningful social contexts put strenuous demands on their memory and created a situation in which their rate of learning had to compete with their rate of forgetting (Burling, 1981).

\section{Implications}

Complementary to quantitative studies on age-related effects in adult L2 acquisition, this descriptive study provides some additional information on what may possibly underlie the effects of age on adult L2 acquisition from the learners' perspective. It is reasonably clear that when the responses of the two AOA groups were compared, there were similarities as well as salient 
differences in their experiences and perceptions of learning ESL in a natural language setting. Although generalizations cannot be made about these two AOA groups of adult learners on the basis of this one study, the interview data reveal the complexity of adult L2 acquisition, which involves factors pertaining not only to the learners themselves, but also to the social context in which the L2 is learned. Understanding adult L2 acquisition as a dynamic process, in which age may co-vary with experiential variables, has educational implications for curriculum development and classroom teaching.

First, if learners' age-related language experiences and perceptions have an effect on their L2 acquisition, then it is no longer adequate to treat all adults as one global group (Harley \& Wang, 1997). In fact, as Long (1990) pointed out:

Therefore it is erroneous to speak of "the adult ESL learner" as if there is a generic adult that can represent all adults.... Physiologically, psychologically, and sociologically, adults are more diverse than children. Variability across the life span generally may be represented by a V. Younger individuals are more likely to share more critical common variables than older adults. (p. 25)

Our perceptions and understanding of adult learners directly affect our curriculum decisions and classroom practice. Differences in learners' experiences and perceptions of $\mathrm{L} 2$ acquisition are valuable information for educators and ESL teachers, suggesting that a centralized ESL curriculum is unlikely to provide for the full range of learning situations in which adult immigrant learners of different age ranges find themselves. Therefore, understanding their learning situations and meeting their specific needs should be the core of any well-established curriculum for adult immigrant learners (Cumming, 1991).

With reference to the age-related differences in learners' experiences with different aspects of English (e.g., listening, speaking, reading, and writing), it becomes clear that $\mathrm{L} 2$ learning objectives may be common to all, but the means of achieving them cannot and, indeed, should not be identical for all. Therefore, there is a need to release adult learners from the expectation to learn all at the same rate. Flexible L2 learning arrangements are needed to attend to the characteristics of adult learners of different age ranges (Seright, 1985).

If, as Wenden (1986) pointed out, learner beliefs about language learning may have an important impact on how they go about it, then it is essential for teachers to know learners' perceptions concerning how L2 should be acquired. With reference to the finding that the later arrivals tended to learn with deliberate reliance on memory, it is important that learning styles be understood and accommodated in choosing instructional approaches; in fact, different instructional approaches should be recognized as necessary in 
L2 teaching and learning. Assuming that some perceptions of L2 acquisition are likely to lead to more effective L2 learning (Horwitz, 1987; Wenden, 1986), teachers should help create a language learning environment where learners can explore alternative ways of learning.

Concerning contact with English, it is important for teachers to understand the gap between many learners' strong desire to have language-acquisition contacts and their feeling of being unable to do so. This gap should be taken seriously. At the curriculum level, creating links between L2 learners and the L2 community should be an essential component of a curriculum for adult immigrant learners (d'Anglejan, 1978; Clément, 1980). Classroom activities should be geared to meet these specific needs of the adult learners. As Singleton (1989) summarized:

"Real" communication presumably refers to using the target language to interact in ways similar to those in which one interacts in one's native language, that is to say, using the language for the sake of relationships to be maintained, business to be transacted, information to be exchanged or aesthetic pleasure to be received or given, rather than for the sake of forms to be practiced. In this sense, real communication can actually occur within the classroom, as the entire literature on communicative language teaching makes clear. (p. 257)

One recommendation put forth by Glass and Denny (1987) was to develop "appropriate communicative contexts [in the classroom], which are reflective of social situations and of personal needs" (p. 115). Similarly, Peirce (1993) has emphasized the importance of teachers' understanding of what opportunities are available for learners to speak the target language outside the classroom. By relating L2 learning to the social context in which it will be used, teachers can help bridge the gap between learning in the classroom and learning outside the classroom.

\section{Conclusion}

In this article I present two AOA groups of women immigrant learners' experiences and perceptions of learning ESL in the Canadian context. Although findings from this study need to be confirmed with other groups of adult learners, particularly male learners, I hope this study will spark further research on the role of age in L2 acquisition. Research among adult learners of a wider age range could produce results for us to get a longer perspective on the rate of decline in L2 proficiency outcomes with increasing age. What might be of particular interest to explore is how age interacts with learner and social variables that may constrain adult learners' language learning opportunities, particularly the relationships between age and L2 contact with the target community, age and anxiety in L2 oral communication, and age and self-confidence in learning an L2. Information on these issues is needed 
if we are to understand how different age groups of adult learners learn in a natural language setting and how they may vary. One important conclusion to be drawn from this study is that the interview is a useful methodology to explore these issues.

\section{Notes}

${ }^{1}$ A stable state indicating that a final level of L2 proficiency has been achieved after a long-term residence in the $\mathrm{L} 2$ environment.

${ }^{2}$ Fluid intelligence, defined by Cattell (1963) as the general ability to perceive and develop new patterns of response, is used to distinguish from crystallized intelligence, which refers to the accumulated knowledge in the form of cultural information.

${ }^{3}$ I observe that this is an or/choice question, which perhaps influenced the kind of responses received. Other questions may have followed naturally from learners' spontaneous observations, for example, "why?"

${ }^{4}$ Interview data are fundamentally qualitative in nature, but some basic statistics may help in the description and interpretation.

${ }^{5}$ EL:1-15 refer to earlier AOA learners and LL:16-30 refer to the later AOA learners.

\section{Acknowledgments}

This article is based on a portion of my doctoral dissertation. I gratefully acknowledge my thesis supervisor Brigit Harley and the members of my committee Alister Cumming and Barbara Burnaby for their guidance. A warm thanks also goes to Birgit for her valuable suggestions on the earlier drafts of the paper and to Patrick Mathews and the anonymous reviewers for their constructive comments and suggestions.

An earlier version of this paper was presented at TESL Ontario Conference '98, Toronto, 19-21 November, 1998.

\section{The Author}

Wendy Wang ( $\mathrm{PhD}, \mathrm{OISE}$, Toronto) has extensive experience in English language training of adult immigrant learners. She is currently a postdoctoral associate in the Department of Educational Theory and Practice, School of Education, SUNY at Albany. Her work is focused on second-language teaching and learning and teacher education.

\section{References}

d'Anglejan, A. (1978). Language learning in and out of classrooms. In J. Richards (Ed.), erstanding second language and foreign language learning: Issues and approaches (pp. 218-237). Rowley, MA: Newbury House.

d'Anglejan, A., \& Renaud, C. (1985). Learner characteristics and second language acquisition: A multivariate study of adult immigrants and some thoughts on methodology. Language Learning, 35, 1-19.

Bialystok, E. (1997). The structure of age: In search of barriers to second language acquisition. Second Language Research, 13, 116-137.

Bialystok, E., \& Hakuta, K. (1994). In other words: The science and psychology of second language acquisition. New York: Basic Books.

Burling, R. (1981). Social constraints on adult language learning. In H. Winitz (Ed.), Native language and foreign language acquisition (pp. 279-290). New York: Annals of the New York Academy of Science (Vol. 379). 
Burton, P. (1993). Women and second language use: An introduction. In P. Burton, K.K. Dyson, \& S. Ardener (Eds.), Bilingual women: Anthropological approaches to second-language use (pp. 1-29). Oxford, UK: Berg.

Cattell, R.B. (1963). Theory of fluid and crystallized intelligence: A critical experiment. Journal of Educational Psychology, 52, 1-22.

Clément, R. (1980). Ethnicity, contact and communicative competence in a second language. In H. Giles, W.P. Robinson, \& P.M. Smith (Eds.), Language: Social psychological perspectives (pp. 147-154). Oxford, UK: Pergamon Press.

Cumming, A. (1991). Identification of current needs and issues related to the delivery of adult ESL instruction in British Columbia. Richmond, BC: Open Learning Agency. (ERIC Document Reproduction Service No. ED 353855)

Cumming, A., \& Gill, J. (1992). Motivation or accessibility? Factors permitting Indo-Canadian women to pursue ESL literacy instruction. In B. Burnaby \& A. Cumming (Eds.), Socio-political aspects of ESL (pp. 241-252). Toronto, ON: OISE Press.

Flege, J.E. (1992). Speech learning in a second language. In C.A. Ferguson \& C. Stoel-Gammon (Eds.), Phonological development: Models, research, implications (pp. 565-604). Timonium, MD: York Press.

Fozard, J.L., Nuttal, R.L., \& Waugh, N.C. (1972). Age-related differences in mental performance. Aging and Human Development, 3, 19-43.

Gardner, R.C. (1985). Social psychology and second language learning: The role of attitudes and motivation. London: Edward Arnold.

Glass, J.C. Jr., \& Denny, J.B. (1987). Second language learning in adulthood. Community/Junior College: Quarterly of Research \& Practice, 11, 103-118.

Harley, B., \& Wang, W. (1997). The critical period hypothesis: Where are we now? In A.M.B. de Groot \& J.F. Kroll (Eds.), Tutorials in bilingualism: Psycholinguistic perspectives (pp. 19-51). Mahwah, NJ: Erlbaum.

Hart, D., \& Cumming, A. (1997). A follow-up study of people in Ontario completing level 3 of the Language Instruction for Newcomers to Canada (LINC) program. Toronto, ON: Modern Language Centre, OISE.

Horwitz, E.K. (1987). Surveying student beliefs about language learning. In A. Wenden \& J. Rubin (Eds.), Learner strategies in language learning (pp. 119-129). Englewood Cliffs, NJ: Prentice-Hall.

Johnson, N., \& Newport, E.L. (1989). Critical period effects in second language learning: The influence of maturational state on the acquisition of English as a second language. Cognitive Psychology, 21, 60-99.

Keller, J.M. (1983). Motivational design of instruction. In C.M. Reigeluth (Ed.), Instructional design theories and models (pp. 386-433). Hillsdale, NJ: Erlbaum.

Klassen, C., \& Burnaby, B. (1993). "Those who know": Views on literacy among adult immigrants in Canada. TESOL Quarterly, 27, 377-397.

Klein, W., \& Dittmar, N. (1979). Developing grammars: The acquisition of German syntax by foreign workers. Berlin: Springer-Verlag.

LINC curriculum guideline (rev. ed.). (1994). Toronto, ON: Ontario Region LINC Advisory Committee, Citizenship and Immigration Canada.

Long, H.B. (1990). Understanding adult learners. In M.W. Galbraith (Ed.), Adult learning methods (pp. 23-37). Malabar, FL: Krieger.

Mellow, D. (1992). A case study of rural second language education: Barriers to adult settlement and education. In B. Burnaby \& A. Cumming (Eds.), Socio-political aspects of ESL (pp. 292-303). Toronto, ON: OISE Press.

Nyikos, M. (1990). Sex-related differences in adult language learning: Socialization and memory factors. Modern Language Journal, 74, 273-287.

Oyama, S. (1976). A sensitive period for the acquisition of a non-native phonological system. Journal of Psycholinguistic Research, 5, 261-283. 
Palij, M. (1990). Acquiring English at different ages: The English displacement effect and other findings. Journal of Psycholinguistic Research, 19, 57-70.

Patkowski, M.S. (1980). The sensitive period for the acquisition of syntax in a second language. Language Learning, 30, 449-472.

Peirce, B.N. (1993). Language learning, social identity, and immigrant women. Unpublished doctoral dissertation, OISE, University of Toronto.

Peirce, B.N. (1995). Social identity, investment, and language learning. TESOL Quarterly, 29, 9-31.

Price, M.L. (1991). The subjective experience of foreign language anxiety: Interviews with highly anxious students. In E.K. Horwitz \& D.J. Young (Eds.), Language anxiety: From theory and research to classroom implications (pp. 101-108). Englewood Cliffs, NJ: Prentice-Hall.

Schumann, J. (1975). Affective factors and the problem of age in second language acquisition. Language Learning, 25, 209-235.

Schumann, J. (1976). Social distance as a factor in second language acquisition. Language Learning, 26, 135-143.

Scott, M.L. (1994). Auditory memory and perception in younger and older adult second language learners. Studies in Second Language Acquisition, 16, 263-281.

Seright, L. (1985). Age and aural comprehension achievement in Francophone adults learning English. TESOL Quarterly, 19, 455-473.

Siegel, L. (1994). Working memory and reading: A life span perspective. International Journal of Behavioral Development, 17, 109-124.

Singleton, D. (1989). Language acquisition: The age factor. Clevedon, UK: Multilingual Matters.

Spolsky, B. (1989). Conditions for second language learning. Oxford, UK: Oxford University Press.

Thompson, I. (1991). Foreign accents revisited: The English pronunciation of Russian immigrants. Language Learning, 41, 177-204.

von Elek, T., \& Oskarsson, M. (1973). Teaching foreign language grammar to adults: A comparative study. Stockholm: Almqvist \& Wiksell.

Wang, W. (1998). Age-related effects in adult second language acquisition: A study of Mandarinspeaking learners of English. Unpublished doctoral dissertation, OISE University of Toronto, Canada.

Wenden, A. (1986). What do second-language learners know about their language learning? A second look at retrospective accounts. Applied Linguistics, 7, 186-201. 